\title{
Factors that influence the retention of social volunteers in the health area: a comparison between the literature and the perception of volunteers
}

\author{
Raquel Pavan Braz ${ }^{1}$, Gilson Brito Alves Lima ${ }^{1}$ \\ ${ }^{1}$ Federal Fluminense University - UFF, Engineering School, Niteroi, RJ, Brazil.
}

How to cite: Braz, R.P. and Lima, G.B.A. (2020), "Factors that influence the retention of social volunteers in the health area: a comparison between the literature and the perception of volunteers", Brazilian Journal of Operations \& Production Management, Vol. 17, No. 2, e2020918. https://doi.org/10.14488/BJOPM.2020.021

\begin{abstract}
Goal: The main objective is to identify the factors that influence the retention of social volunteers in the health area, supported by a comparison between a systematic literature review and the perception of a focus group of volunteers.

Design / Methodology / Approach: Word maps have been developed to compare data obtained from the literature review and the perceptions acquired in a focus group.

Results: the main findings of the research indicate that the factors that influence the retention of social volunteers in the health area need a more comprehensive and systematic investigation, avoiding that any subject or dimension of analysis is not addressed when trying to evaluate the reasons that influence the permanence in volunteer programs. It was also possible to detect some subjective contexts that may influence the volunteers' behavior and decisions.

Limitations of the investigation: The main limitation of the study is the difficulty in generalizing the findings, considering the use of the focus group, which, because it represents a small number of individuals, may not reproduce common sense.

Practical implications: This study seeks to collaborate with future research using a methodology that allows us to evaluate whether what has been questioned in research instruments is close to the reality presented by the context.

Originality / Value: The novelty concerns in the use of world maps to compare the perceptions of the literature findings with the results of a focus group analysis. This paper seeks to contribute to a new look on the qualitative treatment approach of data obtained in research in this area.
\end{abstract}

Keywords: Volunteering; Health; Retention Factors; Word Map.

\section{INTRODUCTION}

This article represents a section of a study that proposed the elaboration of a thematic management instrument to assist the systemic evaluation research on the factors that may influence the retention of social volunteers in the health area (Braz, 2019).

The complexity that volunteer work has shown in recent years (Topp et al., 2015; Grube and Piliavin, 2000) is reflected in the multidimensionality, represented by the numerous motivations and contexts related to the participation of volunteers, and becomes a target of study in the attempt to understand the issues that interfere with their involvement in volunteer programs (Matsuba et al., 2007). According to Ferreira (2012), the analysis of these variables favors the continuity in the provision of voluntary services.

Financial support: None

Conflict of interest: The authors have no conflict of interest to declare

Corresponding author: rauelpbraz@gmail.com

Received: 16 Jan 2020.

Approved: 16 Jan 2020

Editor: Osvaldo L. G. Quelhas. 
The behavior of individuals who propose to develop voluntary activities is heterogeneous (Grube and Piliavin, 2000; Topp et al., 2015) and this complexity is presented in the numerous questions pointed out as the reasons that lead individuals to volunteer work (Kasteng et al., 2016). In the context of these justifications, the belief arises that some individuals are motivated by the very voluntary nature of work, while others seek inspiration from intrinsic interests (Wilson, 2000).

This means that there are individuals who want to engage in volunteering, regardless of the situation, just for the feeling of developing activity aimed at helping others, fulfilling their role as socially responsible citizens. In another context, there is the rational volunteer figure who, besides the feeling of helping others, seeks the opportunity of return in the form of selfbenefit, such as, for example, enriching their curriculum with experiences in the voluntary work area (Rovers et al., 2016).

Therefore, some authors argue that factors related to the motivations of volunteers should be studied considering the context in which it occurs and the characteristics that involve volunteering programs (Grube and Piliavin, 2000; Rovers et al., 2016). The contexts represent the spheres of the environment in which volunteering occurs, and may represent residences, workplaces and regions (cities, countries). The effects of these factors still receive little attention and the impact of organizational, community and regional characteristics on individual decisions still portray a narrow field of knowledge in need of more space for analysis (Wilson, 2000).

The literature, in its many studies, sometimes attaches more importance to certain motivations or scenarios, depending on the focus of the investigation. The proposal to develop an instrument to assist research in this area goes through the intention of systematizing the evaluation process and making it impartial. Therefore, it becomes relevant to analyze if the importance attributed to the variables in the literature approaches the perception of value acquired by the volunteers.

Understanding if what has been questioned by research meets what is important in practice can make the elaboration of future questionnaires aimed at assessing the factors that may influence the retention of volunteers more efficient. For the present study, this analysis will be performed by comparing the word maps that express the results of these two strands.

Besides this introduction, this article presents the following structure: in Section 2, a brief review of the contexts (dimensions of analysis) and the factors that may influence the permanence of social volunteers in volunteer programs in the health area was elaborated; in Section 3, the proposed methodology was presented; in Section 4, the visual explanation allowed the analysis of the results through the comparison of the word maps, being finished by the conclusion of the developed research.

\section{LITERATURE REVIEW}

\section{The dimensions of analysis of volunteering}

What is observed is that some theories try to explain volunteering according to individual characteristics that, in most cases, are divided into reasons related to self-understanding or rational decisions, according to the cost-benefit ratio. On the other hand, others incorporate, in a complementary way, factors related to social issues and organizational activity as levels of analysis (Wilson, 2000).

The functional perspective points to the existence of a wide range of personal and social motivations that interfere with behavior, assuming an interactionist position by recognizing the importance of both individual motivational characteristics and the opportunities offered by the environment (Clary et al., 1998). The analysis proposal of the Volunteering Process Model, by Snyder and Omoto (2008), adopts a methodology developed in four levels: individual, interpersonal/social group, agency/organizational and social/cultural context.

In another approach, Akintola and Chikoko (2016), based on Herzberg's two-factor theory (1987), conducted a study with supervisors of community health programs seeking to 
understand the motivation/satisfaction and demotivation/dissatisfaction factors that guided the accomplishment of their work. The analysis was conducted at three levels: community, organizational (program), political (donor and government agencies).

The model proposed by Ferreira (2012), to evaluate the intention of keeping volunteers in the hospital context, analyzed the variables related to motivations, satisfaction and management factors. The conclusion of this study showed that as many intrinsic factors (individual values) as extrinsic factors (management factors such as recruitment, selection, training, recognition and reward) are important in the satisfaction of volunteers. And that this satisfaction generated plays an essential role in the intention to remain in the practice of volunteering.

Due to the numerous types of approach, Clary et al. (1998) mentioned the concern of some authors with the way the studies on motivation are being conducted regarding the applied concepts and methodologies. Ten years after the statement by Clary et al. (1998), Snyder and Omoto (2008) noted that most empirical work, using the Voluntary Process Model, employs more psychological or traditional analysis issues, focusing on individual-level variables.

It turns out that research on volunteering often ignores the fact that it happens in an organizational context and that its characteristics must be considered, as well as the complexity of volunteer behavior that, in many surveys, is focused on the individual (Grube and Piliavin, 2000). In the same way, Wilson (2000) pointed out that although many volunteer works are organized through family relationships and occur around this structure, the family rarely sets up a dimension of analysis, which can be considered a mistake, given its importance.

The prominent role of the family during the volunteering process was noted by Omoto and Snyder (1995) in finding results in which volunteers gave maximum grade to the agreement that people important to them, including family members, supported their work as a volunteer. Alam et al. (2012) found another family-related element in identifying a significant effect of household responsibilities on retention of volunteers.

At the individual level, some feelings were related to the motivation for volunteer work. Cabot (2016) argued that situations of socioeconomic crises may influence society's participation in volunteering, as they are closely linked to the growth of the feeling of solidarity. Vision also shared by participants of studies conducted by Moyon et al. (2015), in the health area, in which $97 \%$ of respondents expressed that the feeling of solidarity towards people in pain was the main reason for their motivation to participate in the program.

The self-esteem level presented by each individual also represents a stimulating factor for voluntary work. According to Veerasamy et al. (2013), individuals with the highest level of self-esteem are more frequent in volunteering and spend more hours per month on this type of activity.

Identifying the individual with the activity or organization can also interfere with their decision making. Soares (2017), when analyzing the commitment of the employees of a hospital institution, verified the existence of volunteers who had already belonged to the hospital staff before retiring. According to him, this attitude was the result of the affective commitment that these individuals had with the institution.

Another issue related to the individual level is the search for paid work, which has been cited in recent studies on motivation in the area of volunteering. Although voluntary work is not intended to compensate for the service provided, the pursuit of paid work can also serve as a motivator for pursuing this type of activity. Arinze-Onyia et al. (2015) concluded that individuals who are unemployed tend to join volunteer programs more easily with the expectation that through them they will get paid employment in the future, while individuals who are already employed are willing to volunteer simply for the volunteering fact of helping the needy.

Motivation often comes from a sense of commitment to the community and a willingness to feel useful to society (Pourtau et al., 2016) or even as a way to make friends or develop social bonds (Omoto and Snyder, 1995). Penner (2002) argues that some individuals may 
volunteer due to the existence of social pressure, which occurs when they start from a subjective assessment of the expectations of others.

Organizations also play a prominent role in the volunteerism scenario, given that, generally, voluntary practices occur in this context (Penner, 2002). With the transposition of volunteer work from a systematic based on sporadic actions to a frequently provided service and rule making, there was a need to organize and manage volunteers. This new configuration, characterized by the professionalization of volunteering, seeks to organize itself according to the precepts of effective management, since its absence can impact the retention of the volunteer (Ramos and Domingues, 2016). Thus, it is necessary to analyze the organizational variables in the behavior of volunteers (Penner, 2002).

The institutional environment is one of the major influencers on motivational issues, interfering with the intrinsic motivation of volunteers by meeting their basic psychological needs. Since it is a constantly changing scenario, motivation levels also vary over time according to the organization's ability to meet the needs of volunteers (Bidee et al., 2017). Consequently, the feeling of satisfaction with the organization, according to Omoto and Snyder (1995), may influence the retention of these individuals.

Some organizational components as, for example, interpersonal relationships, including team relationships, constitute a positive point for the volunteer's engagement with the program. This is because there is a feeling that each individual has the ability to interfere with the other's involvement, creating ties between the participants and favoring the establishment of networks, and may encourage the permanence for a longer period (Sarti et al., 2017). The construction of these social networks is positive because it causes the feeling of inclusion, which generates a sense of belonging and makes them feel identified as peers and recognized for their contributions, thus causing greater satisfaction (Bidee et al., 2017).

They can also influence the sustainability of programs through the recruitment of future volunteers, as they facilitate the dissemination of the process through word-of-mouth communication between individuals with similar profiles and tend to be more credible, generating a more positive response than communication through formal dissemination means (Sarti et al., 2017). Considering that volunteers' intention to stay may increase as the organization's ability to meet its motivations (liménez et al., 2010), recruitment and selection play a key role in the volunteering process, as by knowing the profile and motivations of volunteers, marketing actions can be directed to attract and select the most appropriate individuals (Ferreira, 2012; Penner, 2002).

Marketing actions are also important during the period of the volunteers stay in the program, since they have a strategic participation in the process of disclosing the organizational objectives, information about the activities and defining the role of the individuals involved in the volunteering process. (Ferreira, 2012). And since this process develops within organizational structures, it is necessary to identify the volunteer with the organization, so that it can continue performing this type of activity for a longer period (Grube and Piliavin, 2000).

Recognition and reward were also identified as management factors that influence the practice of volunteering (Ferreira, 2012). The acquisition of new skills is essential for the continuity of activities and to maintain the commitment of volunteers, especially in health related areas. When surviving volunteers and sick patients are involved, for example, there is a need for them to understand the challenges surrounding this relationship and how they should use their experience with the disease in a useful way for the treatment being developed (Pourtau et al., 2016). Moreover, the importance of being prepared to develop their activities and the action of organizations to promote their training makes them feel more valued and, consequently, increase their degree of satisfaction (Ferreira, 2012).

A counterpoint in the discussion about the motivation and satisfaction of volunteers manifests itself from the debate about the existence of stressors caused by the nature of volunteer activities, which can lead to stress and burnout. (Crippa et al., 2014; Moniz and Araújo, 2006). Burnout is characterized by the total exhaustion resulting from the activities developed, but there is no "closed" concept about its nature. The factors that cause their 
condition inhabit a subjective sphere (Vieira, 2010), which may involve determinants related to the volunteer's physical or mental health (Moniz and Araújo, 2006).

Moniz and Araújo (2006) conducted a study on the perception of volunteers in cancer patients institutions and support institutions for HIV carriers, their performance and the degree of stress and burnout presented and concluded about the value of this type of evaluation. They also pointed to another management issue of volunteer programs, which is the need to support the activities developed, even in order to prevent disease situations. Snyder and Omoto (2008) believe that working with volunteer activities that are involved in health issues can generate more stress for volunteers.

Configuring yet another component of the institutional environment, the institution's organizational culture is responsible for the success of the work as it promotes the connection of all demands involving volunteers, serving as the basis for the well-being of those involved. Reciprocity in this environment is one of the factors responsible for the personal satisfaction of volunteers and, added to emotional and cognitive issues, represents one of the main causes of engagement and interest in volunteer work (Sarti et al., 2017).

Turning to the political sphere, this is justified given the numerous examples of community-based volunteer programs that are carried out with NGOs (Topp et al., 2015; Olang'o et al., 2010), and which usually work in partnership with governments. Akintola and Chikoko (2016) identified that problems related to the scarcity of government resources and financing may impact the functioning of these organizations at the organizational level and, consequently, the provision of services. Concerning the supervisors of these organizations, this issue resulted in factors that provided dissatisfaction, which were also noted in relation to the challenges of partnerships with government agencies.

For the present study, the idea of context defined by Wilson (2000) assumes the role of influence dimension in the behavior of volunteers. The importance of the influence of contexts or dimensions on the behavior of volunteers is pointed out in numerous studies (Grube and Piliavin, 2000; Wilson, 2000; Rovers et al., 2016), but often the approach adopted does not cover all possibilities. This is because research on volunteering does not always promote categorization explicitly and in a structured way, as there is no proposed standard. Few studies seek to explicitly define the dimensions studied as did Alam et al. (2012) who, in their studies, considered issues related to the individual, family, community and organizational contexts.

Each dimension of analysis has numerous subdivisions that represent several subjects that reflect their characteristics. In the next item, some of these subjects and their variables that may influence the volunteering process will be explained.

\section{The influencing factors of volunteering}

The literature sometimes adopts the word "factors" to characterize the reasons that may influence the volunteer's decision to remain in volunteer programs, but the use of the word "variables" is also observed. In this study, the term "factors" was adopted predominantly, but also allowing the use of the term "variables" with respect to the approach of some authors, provided that there is no change in the proposed semantic value.

The variables that influence the behavior of volunteers and consequently their intention to remain volunteers arouse great interest and have been studied for some time (Penner, 2002; Jiménez et al., 2010). According to Ferreira (2012), they may be divergent or change over time, thus fitting an investigation on these data in order to assist mainly in the recruitment of new volunteers. Similar reflection led some authors to analyze volunteering as a process that occurs along a timeline, dividing it into stages (Chacón et al., 2007; Omoto and Snyder, 1995; Penner, 2002).

Chacón et al. (2007) proposed a model of investigation of the intention to remain in voluntary service, which divides the analysis into periods of six months, one year and two years - Three-Stage Model of Volunteers' Duration. Jiménez et al. (2010) applied this model by addressing variables related to sociodemographic characteristics (age, gender, educational level, work situations), volunteer satisfaction (motivations, job satisfaction, and satisfaction 
with management). organizational commitment, identity of the volunteer's role, emotional fatigue, intention to remain in service, and how many days and hours per week were spent on volunteer activities and how long it took to get to the organization.

Snyder and Omoto (2008) also presented a volunteer analysis model based on three temporal stages (antecedents, experience and consequences) that present variables at each level of analysis (individual, interpersonal/social group, agency/organizational and social/cultural context). At the individual level were identified the characteristics of personality, motivational, circumstances of the individual's life, satisfaction, stigma, organizational integration, change of knowledge and attitude and health. At the interpersonal/social group level, the characteristics of group association, rules, help relationship, collective esteem, social network composition and relationship development were explored.

The agency/organization level involved questions about recruitment, training, organizational culture, volunteer assignments, volunteer retention and job evaluation. The social/cultural context dealt with ideologies, programs and institutions of services, service provision, program development and social capital.

In the model suggested by Penner (2002), situational factors and voluntary social pressure are outlined, as well as sociodemographic, organizational variables (attributes, practices and relationship with the organization), personal beliefs and values, prosocial personality and motives related to volunteering. Ferreira (2012) also proposed an investigation on the intention of the volunteers to stay and, after searching the literature, chose to use variables related to their motivations, satisfaction and management factors. Motivations and satisfaction were measured at the level of the individual's sphere and management factors represented the intrinsic issues of the organization.

Successive surveys involving satisfaction issues to measure volunteers' intention to remain are understandable, as previous studies have indicated a greater likelihood of continuing volunteering when the volunteer is satisfied (Cnaan and Goldberg-Glen, 1991; Omoto and Snyder, 1995). But in order to understand what influences the volunteering process and, consequently, the behavior of volunteers, we must consider the complexity of the scenario and the variables surrounding the situation.

As Penner (2002) argues, an interactionist perspective should be addressed, given that none of the variables alone can provide a complete explanation of the motives involved. This study does not claim to exhaust all possible variables, given the complexity of human behavior, but seeks to gather as many variables as can influence the process studied, serving as an incentive for the development of future research. The actions to be developed by this investigation will now be structured.

\section{METHODOLOGY}

To analyze the factors that influence the retention of volunteers, a literature review was initially performed based on the adaptation of the PRISMA recommendation - Main Items to Report Systematic Reviews and Meta-analyzes (Moher et al., 2015), seeking greater efficiency in obtaining the studies to be used as theoretical support for the present work (Braz and Lima, 2019). At the end of this process, 13 articles were selected, which allowed the mapping of influence factors and the identification of the dimensions of analysis that are usually addressed in research on retention of volunteers in the health area. Obtaining these data substantiated the elaboration of a research instrument that was subsequently applied to a focus group composed of six specialists from the social volunteering field in the health area. The following figure represents the systematic used. 


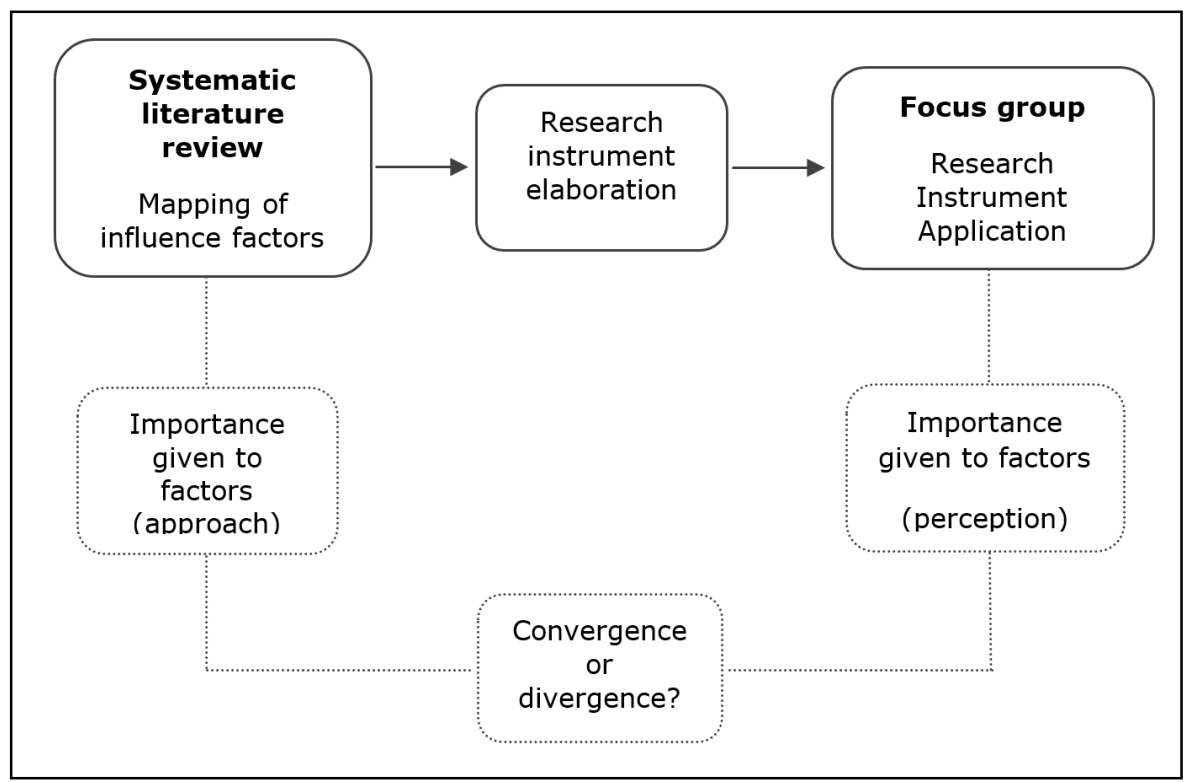

Figure 1. Structure of the methodology used. Source: Own elaboration

As shown in Figure 1, the results of the two phases were compared in order to find out if there was any kind of convergence between them, given that the same factors were used in both stages. For the elaboration of the word map referring to the systematic review, we considered the number of times that the same factor was questioned among the 13 articles analyzed.

Regarding the focus group, a form was applied to measure the degree of importance of the factors, considering the perception of the participants. For the elaboration of the word map, the weight given to each factor resulted from the application of the mode to the results obtained by using a Likert scale. This scale was structured with five evaluation points (1 - No importance, 2 - Little importance, 3 - Reasonably important, 4 - Important, 5 - Extremely important).

\section{RESULTS ANALYSIS AND DISCUSSION}

The analysis and discussion of the results sought to build a dialogue between the literature and the focus group. The mapping of the factors present in retention surveys allowed the identification of the issues that have been addressed when intending to evaluate the reasons that influence the permanence in volunteer programs. It was also possible to detect the contexts that may influence the behavior and decisions of volunteers.

The data provided by the systematic review phase allowed the identification of five dimensions of the analysis: individual, family, social, organizational and political. From these dimensions, factors were mapped that resulted in the following word map, using the wordclouds tool. The map shows the importance of each mapped factor by giving weight to the approach rates. That is, the greater the citation of a given subject, in the studies analyzed, the greater its representation on the map. 


\section{Interpersonal relations Services/activities Training Enhancement/self-steem Family characteristics Recruitmentincentives Workload Job Individual Experience Expectancylndividual Location

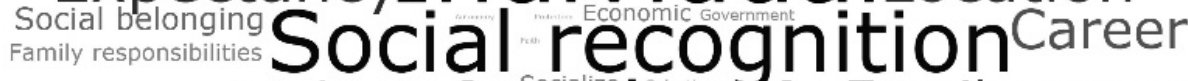 ValuesAcademic Family support volunteer heas ACaden Social support Organizational monitoring Infrastructure Hunderstanding}

Figure 2. Word map of systematic review factors. Source: Tool Usage wordclouds

Considering Figure 2, we observe that factors related to individual characteristics (individual), such as name, age and gender, are frequently questioned in research on the retention of social volunteers in the health area, as well as questions about the academic background of volunteers (academic), both belonging to the individual dimension. With a similar approach to the latter, factors related to social recognition, from the social dimension, and incentives, belonging to the organizational dimension, stand out.

Then, issues related to social support and family characteristics are strongly present, and later the factors related to organizational monitoring and training. With a lower approach, but still expressive, the factors related to the infrastructure of the volunteer organizations, the values and expectations of the volunteers and the location where the volunteer actions are carried out or where the volunteers' home is located appear.

These results show that the factors referring to the individual and organizational dimensions were the ones that were most present in the mapped articles. Less frequently, words related to the social and family dimensions are found. The political dimension, however, was not expressive in the word map of the systematic review.

The wordclouds tool was also used to generate the word map to organize the subjects according to the level of importance given to each factor by the focus group. The data used resulted from the application of questionnaires of importance, representing the quantitative findings. The result is in the following figure. 


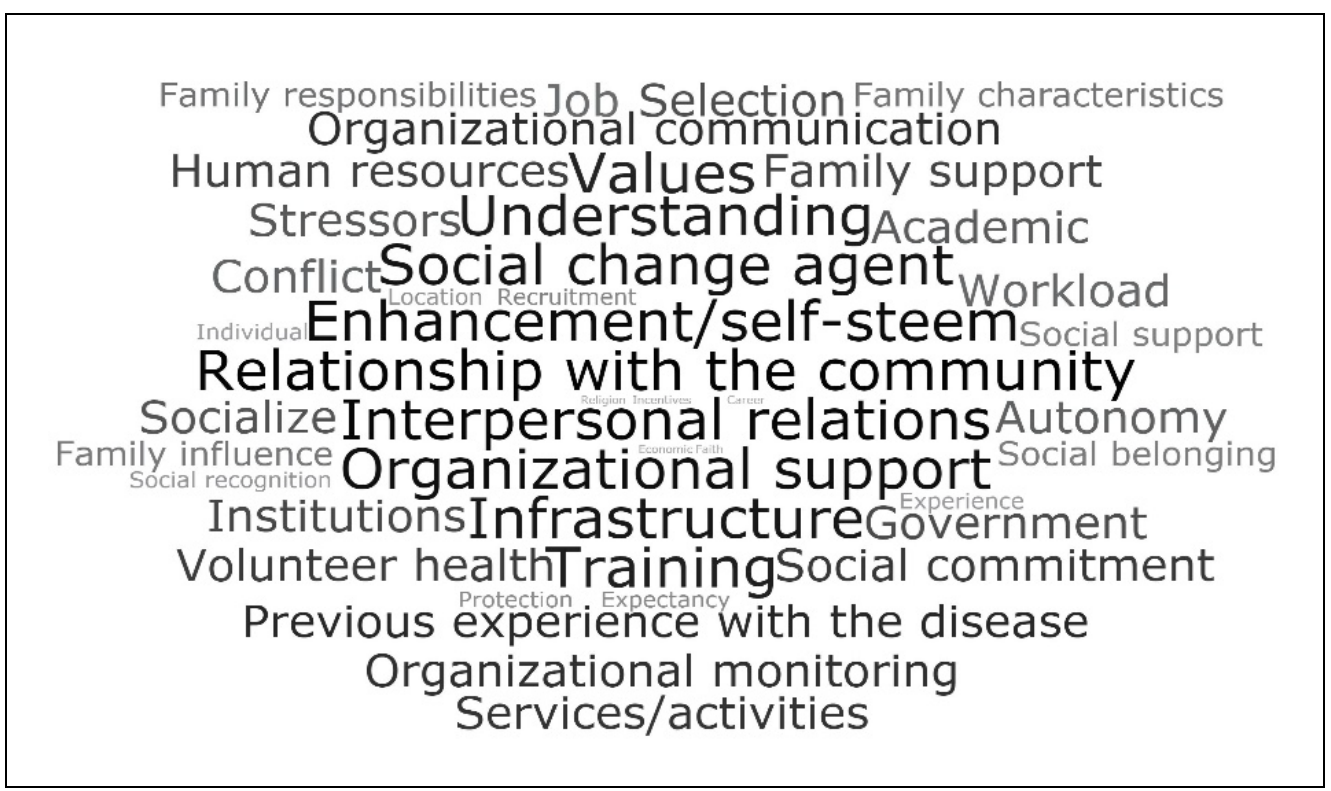

Figure 3. Word map of focus group factors. Source: Tool usage wordclouds

As seen in Figure 3, a significant number of factors had their importance considered during the development of the focus group. For professionals, with extensive experience in the area of volunteering, who participated in such practice, the factors that stood out as influencing the volunteer's permanence in the volunteer programs are described below, according to their respective dimension of analysis:

a) individual dimension: personal improvement (Enhancement/Self-steem), understanding, individual values, academic characteristics of the volunteer, their employment situation (Job), previous experience with the disease, volunteer health and conflicts;

b) family dimension: family support;

c) social dimension: desire to socialize and feelings linked to the figure of agent of change and social commitment;

d) organizational dimension: organizational support, relationships between voluntary organizations and the community, infrastructure for volunteer programs, interpersonal relationships, training, organizational communication, services and activities, workload, selection of volunteers, management of human resources, stressors resulting from the practice of volunteering, autonomy and organizational monitoring;

e) political dimension: relationship between volunteering institutions (Institutions) and government support (Government).

The result of the word map of the focus group showed that a greater number of factors belonging to the organizational dimension were addressed, being followed by the individual and social dimensions, respectively. The family dimension showed little representativeness. The political dimension highlighted the two factors given to it in the systematic review phase as important.

The interaction of word maps of the two phases of this research, systematic review and focus group, illustrates the comparison of the obtained data and explains the difference of approaches observed in these two moments. The result is detailed in Figure 4. 


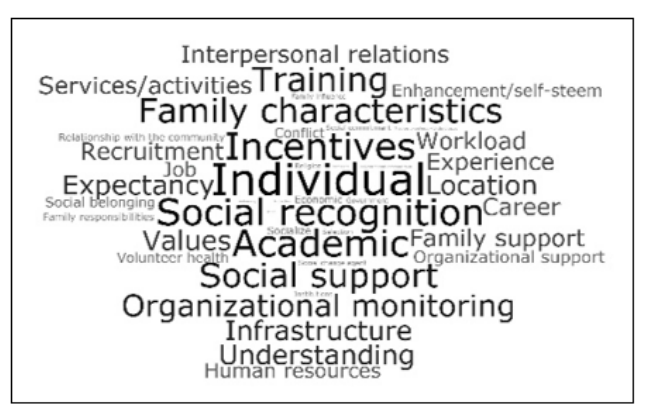

Word map of systematic review factors

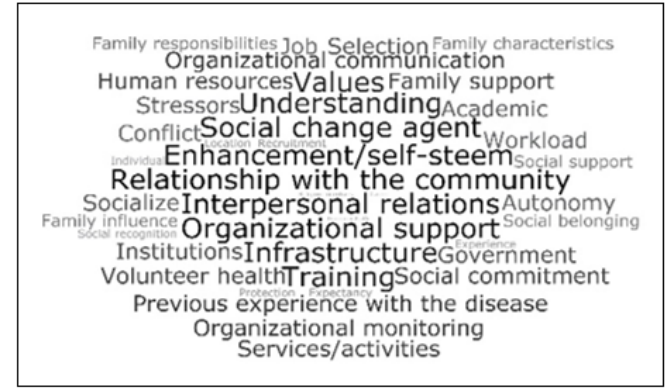

Word map of focus group factors

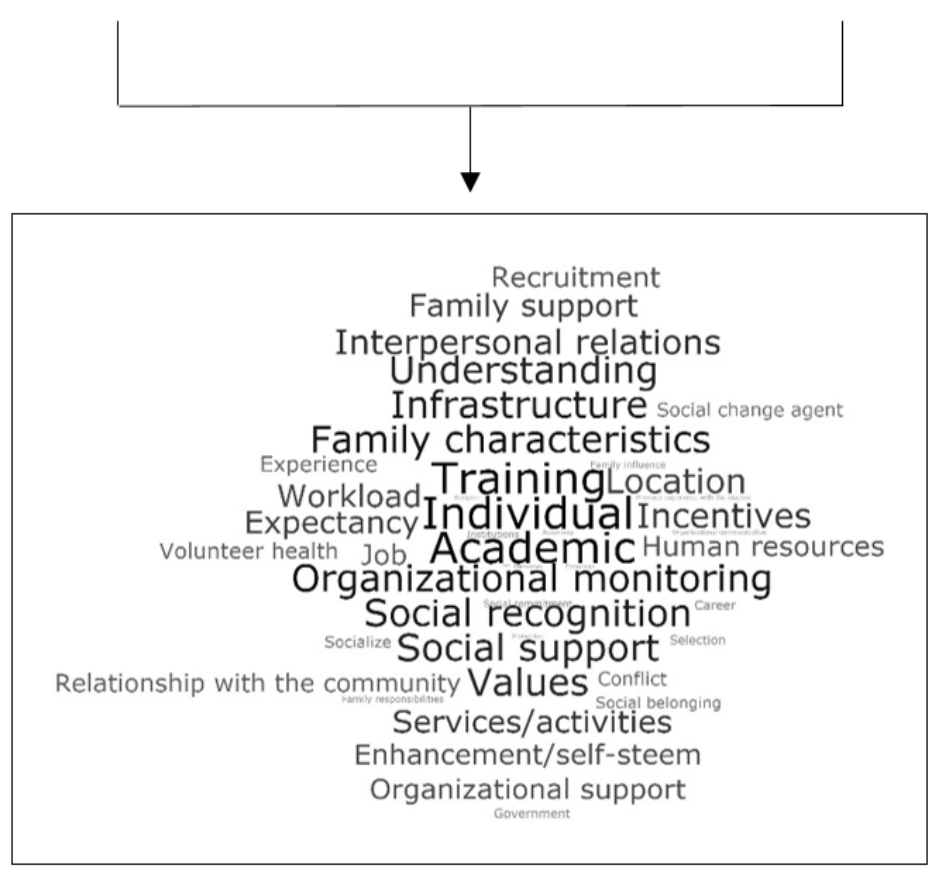

Systematic Review + Focus Group

Figure 4. Relationship between search word maps. Source: Own elaboration

When comparing the two word maps, the first inference to be understood is the difference in the approach of the factors in each phase. On the literature map, a small number of words have a noticeably larger size in relation to the others. This shows that the literature seems to present an analysis behavior centered on the approach of some specific subjects more frequently. In the focus group map, the attenuated difference in size between the words shows a possible more comprehensive questioning and a more balanced approach on the issues that can interfere in the retention of the volunteers.

Another issue to be observed is whether the factors that stood out the most in each map coincide, according to the importance given to them. In this regard, we notice that, in contrast to the results of the focus group, the literature provides more space for factors related to individual characteristics, organizational incentives, recognition and social support. In contrast, the focus group addresses issues such as volunteer autonomy, the selection process and the feeling of an agent of social change that have an irrelevant approach in the literature. On the other hand, topics such as workload, training and infrastructure were present in an expressive way in the two word maps.

Analyzing the word map resulting from the interaction of the systematic review vision map and the focal group vision map, there is an empowerment of individual and academic words, coinciding with the trend of the literature review map. Organizational monitoring, training and social recognition were also highlighted. The first two had a significant approach on the two maps individually, while social recognition was more expressive on the map of the systematic review. 
The systematic review map provides individual issues with greater emphasis than other subjects, while the focus group map focuses more on the organizational context. However, when providing the condensation of these two results, the valuation of individual, organizational and social factors is observed in a more approximate way, reaching a systemic analysis of the factors that can influence the issue of retention, considering the maximum of contexts involved in the volunteering process.

The results show that in some points there is convergence in the approach provided to certain subjects, but it is also observed that the approach of some subjects is more noticed either in the literature or in the practice experienced by the focus group. This data comparison shows that, although one factor was more expressively addressed in only one of the research phases, the sum of the results of the two phases brings its importance to the debate. And it justifies the systematic used by this study, in order to allow gathering factors present in different approaches, as long as their importance has been verified.

Therefore, it is observed that the results obtained in the present study converge with what the literature recommends, regarding the spheres and the factors to be analyzed. Factors related to individual issues were significantly present in the two phases of the research, showing its importance for the discussion of the subject (Ferreira, 2012; Snyder and Omoto, 2008; Clary et al., 1998). The space occupied by the figure of the family structure and the relationships that involve this dimension, pointed out by Wilson (2000), was also observed.

The social sphere, representing the community, also revealed its relevance in being addressed (Akintola and Chikoko, 2016; Snyder and Omoto, 2008). As well as the organizational factors, already mentioned by Ferreira (2012), which showed that issues related to the management of volunteer programs revealed a strong tendency in the individual's decision to remain as a volunteer. Therefore, it is essential to address these factors in research focused on retaining this workforce (Akintola and Chikoko, 2016; Snyder and Omoto, 2008; Wilson, 2000).

\section{STUDY LIMITATIONS}

In the context of the chosen methodology, considering that one of its phases consists of a systematic review of the literature, carried out through bibliographic research, the sources are limited to the consultation bases selected by the researcher, which may interfere in the quality of data and work developed. It is also worth noting the difficulty in generalizing the empirical results (Bunchaft and Gondim, 2004), since the second part of the investigation had as a source of data the development of a focus group with six participants. Even if composed of specialists in the area under discussion, the results may not represent common sense.

\section{CONCLUSION}

This article sought to contribute to the analysis of the approach of factors that may interfere in the retention of social volunteers in the health area, performed, at first, by the literature, and later by the focus group. The methodology was structured through visual explanation, based on the elaboration of word maps in order to facilitate the perception of the importance given to the factors related in each phase.

The analysis of the word maps in the literature, the focus group and the relationship between them helped to understand, among the factors and dimensions addressed, which are more relevant to the debate of the subject at each moment. The word map in the literature showed a tendency to investigate more focused on issues of individual and social dimensions. The focus group word map also addressed factors of the individual, family, social and political dimensions, presenting an apparent harmony concerning the approach of the factors in a more systemic way. However, at the same time, it stated that, in practice, organizational issues can directly affect the volunteer's decision to remain in the volunteer programs and, perhaps, this is the reason for a greater approach to these factors.

It was possible to conclude that there is a need to promote a balance in the attribution of importance to the factors that will be used when preparing the research form in order to 
prepare a more comprehensive and systematic investigation, without any subject or dimension being left out. Despite the elaboration of the word map from the combination of the two maps, the literature and the focus group, the one that came closest to a more balanced structure configured the layout on the map of the focus group.

Given that the study did not seek to exhaust all factors that may influence the retention of social volunteers in the health area and considering the heterogeneous characteristics presented by each volunteer program, even those belonging to different areas of the study, we suggest new investigations into the factors that show some importance to the volunteer's decision to remain linked to this type of activity.

\section{REFERÊNCIAS}

Akintola, O. and Chikoko, G. (2016), "Factors influencing motivation and job satisfaction among supervisors of community health workers in marginalized communities in South Africa", Human Resources for Health, Vol. 14, No. 1, pp. 54.

Alam, K., Tasneem, S. and Oliveras, E. (2012), "Retention of female volunteer community health workers in Dhaka urban slums: a case-control study", Health Policy and Planning, Vol. 27, No. 6, pp. 477-86.

Arinze-Onyia, S.U., Modebe, I., Aguwa, E.N. et al. (2015), "Assessment of knowledge and factors that may predict willingness to volunteerism: A pilot study of community-directed distributors in Anambra State", Nigerian Journal of Clinical Practice, Vol. 18, No. 1, pp. 61-7.

Bidee, J., Vantilborgh, T., Pepermans, R. et al. (2017), "Daily motivation of volunteers in healthcare organizations: relating team inclusion and intrinsic motivation using self-determination theory", European Journal of Work and Organizational Psychology, Vol. 26, No. 3, pp. 325-36. http://dx.doi.org/10.1080/1359432X.2016.1277206.

Braz, R.P. (2019), Instrumento Temático para Avaliações Sistêmicas dos Fatores Que Influenciam a Retenção de Voluntários Sociais na Área da Saúde, Dissertação de Mestrado em Sistemas de Gestão, Universidade Federal Fluminense, Niterói, RJ.

Braz, R.P. and Lima, G.B.A. (2019), "Fatores temáticos e dimensões de influência do voluntariado social na área da saúde: uma revisão sistemática", in Congresso Nacional de Excelência em Gestão, Rio de Janeiro.

Bunchaft, A.F. and Gondim, S.M.G. (2004), "Grupos focais na investigação qualitativa da identidade organizacional. Exemplo de aplicação", Estudos de Psicologia, Vol. 21, No. 2, pp. 63-77.

Cabot, H. (2016), "Contagious" solidarity: reconfiguring care and citizenship in Greece's social clinics", Social Anthropology, Vol. 24, No. 2, pp. 152-66.

Chacón, F., Vecina, M.L. and Dávila, M.C. (2007), "The three-stage model of volunteers' duration of service", Social Behavior and Personality, Vol. 35, No. 5, pp. 627-42. http://dx.doi.org/10.2224/sbp.2007.35.5.627.

Clary, E.G., Snyder, M., Ridge, R.D. et al. (1998), "Understanding and assessing the motivations of volunteers: a functional approach", Journal of Personality and Social Psychology, Vol. 74, No. 6, pp. 1516-30. http://dx.doi.org/10.1037/0022-3514.74.6.1516.

Cnaan, R. and Goldberg-Glen, R. (1991), "Measuring motivation to volunteer in human services", The Journal of Applied Behavioral Science, Vol. 27, No. 3, pp. 269-84. http://dx.doi.org/10.1177/0021886391273003.

Crippa, A., Isidoro, T. and Feijó, A.G.S. (2014), "Voluntariado e saúde", Revista AMRIGS, Vol. 58, pp. $247-51$.

Ferreira, M.J.R.L. (2012), Motivaçãoes e Gestão do Voluntariado no Setor Hospitalar em Portugal, Tese de Doutoramento em Ciências Empresariais, Faculdade de Economia, Universidade do Porto, Porto.

Grube, J.A. and Piliavin, J.A. (2000), "Role identity, organizational experiences, and volunteer performance", Personality and Social Psychology Bulletin, Vol. 26, No. 9, pp. 1108-19. http://dx.doi.org/10.1177/01461672002611007.

Herzberg, F. (1987), "One more time: how do you motivate employees", Harvard Business Review, Vol. 65, pp. 109. 
Jiménez, M., Fuertes, F. and Abad, M. (2010), "Differences and similarities among volunteers who drop out during the first year and volunteers who continue after eight years", The Spanish Journal of Psychology, Vol. 13, No. 1, pp. 343-52. http://dx.doi.org/10.1017/S1138741600003905.

Kasteng, F., Settumba, S., Kallander, K. et al. (2016), "Valuing the work of unpaid community health workers and exploring the incentives to volunteering in rural Africa", Health Policy and Planning, Vol. 31, No. 2, pp. 205-16. http://dx.doi.org/10.1093/heapol/czv042.

Matsuba, M.K., Hart, D. and Atkins, R. (2007), "Psychological and social-structural influences on commitment to volunteering", Journal of Research in Personality, Vol. 41, No. 4, pp. 889-907. http://dx.doi.org/10.1016/j.jrp.2006.11.001.

Moher, D., Liberati, A., Tetzlaff, J. et al. (2015), "Principais itens para relatar revisões sistemáticas e metaanálises: a recomendação PRISMA", Epidemiologia e Serviços de Saúde, Vol. 24, No. 2, pp. 335-42.

Moniz, A.L.F. and Araujo, T.C.C.F. (2006), "Trabalho voluntário em saúde: auto-percepção, estresse e burnout", Interação em Psicologia, Vol. 10, No. 2, pp. 235-43. http://dx.doi.org/10.5380/psi.v10i2.7680.

Moyon, M., Hertzog, M., Vogel, T. et al. (2015), "Place of volunteers in home care setting for taking care of individuals with Alzheimer's disease and related dementia: Qualitative survey in a specialized unit", Neurologie, Psychiatrie, Gériatrie, Vol. 15, No. 87, pp. 147-57. http://dx.doi.org/10.1016/j.npg.2014.10.006.

Olang'o, C.O., Nyamongo, I.K. and Aagaard-Hansen, J. (2010), "Staff attrition among community health workers in home-based care programmes for people living with HIV and AIDS in western Kenya", Health Policy, Vol. 97, No. 2-3, pp. 232-7.

Omoto, A.M. and Snyder, M. (1995), "Sustained helping without obligation: Motivation, longevity of service, and perceived attitude change among AIDS volunteers", Journal of Personality and Social Psychology, Vol. 68, No. 4, pp. 671-86. http://dx.doi.org/10.1037/0022-3514.68.4.671.

Penner, L.A. (2002), "Dispositional and organizational influences on sustained volunteerism: an interactionist perspective", Journal of Social, Vol. 58, No. 3, pp. 447-67.

Pourtau, L., Taleb, S., De Oliveira, J.-P. et al. (2016), "Cancer survivors" as voluntary helpers in cancer associations in France: limits of the balance between service offer and social demand", Journal of Cancer Education, Vol. 31, No. 3, pp. 460-5.

Ramos, S.P. and Domingues, M.J.C.S. (2016), "Gestão do voluntariado: um panorama dos estudos realizados no Brasil", Revista Foco, Vol. 9, No. 1, pp. 198-214. http://dx.doi.org/10.28950/1981223x_revistafocoadm/2016.v9i1.223.

Rovers, J., Japs, K., Truong, E. et al. (2016), "Motivations, barriers and ethical understandings of healthcare student volunteers on a medical service trip: a mixed methods study", BMC Medical Education, Vol. 16, No. 1, pp. 94. http://dx.doi.org/10.1186/s12909-016-0618-0.

Sarti, A.J., Sutherland, S., Landriault, A. et al. (2017), "Exploring the components of physician volunteer engagement: a qualitative investigation of a national Canadian simulation-based training programme", BMJ Open, Vol. 7, No. 6, pp. e014303. http://dx.doi.org/10.1136/bmjopen-2016-014303.

Snyder, M. and Omoto, A.M. (2008), "Volunteerism: social issues perspectives and social policy implications", Social Issues and Policy Review, Vol. 2, No. 1, pp. 1-36.

Soares, J.V. (2017). Maturidade da Gestão de RH e Comprometimento do Funcionário: um Estudo em Hospitais da Cidade de Muriaé (MG), Dissertação de Mestrado em Sistemas de Gestão, Escola de Engenharia, Universidade Federal Fluminense, Niterói, RJ, available at: https://app.uff.br/riuff/handle/1/4513 (accessed 27 December 2018).

Topp, S.M., Price, J.E., Nanyangwe-Moyo, T. et al. (2015), "Motivations for entering and remaining in volunteer service: findings from a mixed-method survey among HIV caregivers in Zambia", Human Resources for Health, Vol. 13, No. 1, pp. 72.

Veerasamy, C., Sambasivan, M. and Kumar, N. (2013), "Individual Skills Based Volunteerism and Life Satisfaction among Healthcare Volunteers in Malaysia: Role of Employer Encouragement, SelfEsteem and Job Performance, A Cross-Sectional Study", PLoS One, Vol. 8, No. 10, pp. e77698. 
Factors that influence the retention of social volunteers in the health area: a comparison between the literature and the perception of volunteers

Vieira, I. (2010), "Conceito(s) de burnout: questões atuais da pesquisa e a contribuição da clínica", Revista Brasileira de Saúde Ocupacional, Vol. 35, No. 122, pp. 269-76. http://dx.doi.org/10.1590/S030376572010000200009.

Wilson, J. (2000), "Volunteering", Annual Review of Sociology, Vol. 26, No. 1, pp. 215-40. http://dx.doi.org/10.1146/annurev.soc.26.1.215.

Author contributions: All authors contributed equally to the development of the article. 